\title{
EVALUATION OF THE EFFECTS OF PALEOLITHIC DIET IN MUSCLE MASS, MUSCLE STRENGTH, PERFORMANCE AND ANTHROPOMETRY OF CROSSFIT PRACTITIONERS IN THE CITY OF LIMEIRA
}

\author{
Daniela B. Casentini (IC), Sara R. S. Pinheiro (IC), Matheus U. A. Loureiro (PG), Elizabeth C. Maggioni \\ (IC), Marcos S. Francischini (IC), Lucas Leite (PQ), Fúlvia M. Gobatto (PQ), Cláudio Alexandre \\ Gobatto (PQ), Patrícia Lopes Campos Ferraz (PQ)
}

\begin{abstract}
The CrossFit is a sport that constantly advocates a varied diet, with functional movements performed at high intensity, with the aim of promoting health to their followers. They was suggested to joining the Paleolithic diet in order to improve health and muscle definition. Thus, a study was conducted by partial randomization, blind, parallel groups, being selected 14 individuals from a CrossFit studio in the city of Limeira, male and divided into two groups, one following the Paleolithic diet, with $40 \%$ carbohydrate, $30 \%$ protein and $30 \%$ lipids, and the other the control diet with $60 \%$ carbohydrate, $30 \%$ protein and $10 \%$ lipids, for 8 weeks, with the minimum set of 24 training sessions. Of the 14 selected, only 10 completed the study. Pre and post intervention aspects were analyzed as the evaluation of food consumption, power test 5 maximum repetitions for lower and upper limbs, running 1000 meters for performance, anthropometry and bioelectrical impedance for body composition analysis, WOD time-trial and POMS questionnaire for evaluation of mood and results were compared in each group.
\end{abstract}

Key words: Low-carbohydrate diet, exercise, CrossFit.

\section{Introduction}

The CrossFit consist of an interval-training regimen with functional movements performed at high intensity, which is used as an alternative to traditional resistance training ${ }^{1}$. It motivates individuals of all ages to engage in this practice to promote physical fitness and improvement in aerobic conditioning, aiming health and fitness. It is common among followers the adoption of paleolithic diet in order to improve body composition, which is characterized by increased protein content, total fat, and fiber, and reduced intake of sodium, sugar, dairy, and refined foods. The study evaluated the effect of paleolithic diet in maintaining muscle mass, muscle strength, performance and anthropometry in CrossFit athletes compared to the control diet.

\section{Results and Discussion}

Fourteen subjects, aged $27 \pm 5 y$, with more than 90 days of training, heathy and refraining the use of supplements for at least 30 days were selected. They were divided into 2 groups according to their performance in WOD time trial: Paleolithic and Control. Of the 14,10 completed the study $(n=4$ Paleo Group $\mathrm{n}=6$ control group). In the postintervention moment in WOD test, the Paleo group decreased run time of $7.5 \pm 1.5$ to $6.5 \pm 1.0$ and the Control increased from $9,45 \pm 2$ to $9,8 \pm$ 5,7 minutes. In the test of 1000 meters, the Paleo group decreased their time on average $3.6 \pm 0.5$ to $3.4 \pm 0.6$ minutes and group $2,4.0 \pm 0.8$ to 3.8 $\pm 0,6$ minutes, both not statistically significant. Compared to pre intervention moment in 5RM test of strength on the bench press, the Paleo group decreased on average $109.2 \pm 15.1 \mathrm{~kg}$ to $98.9 \pm$ $16.4 \mathrm{~kg}(\mathrm{p}<0.05)$ and of legpress $184.54 \pm 17.8$ to $205.2 \pm 22.5 \mathrm{~kg}$. The control group, on the bench press, $109.3 \pm 8.8$ to $102.4 \pm 6.8 \mathrm{~kg}$, and of legpress $194.4 \pm 26.2$ to $184.2 \pm 27.5 \mathrm{~kg}$, without statistical significance. Regarding the \% of muscle mass, the Paleo group increased on average 81,6 $\pm 5,3$ to $84,1 \pm 4,9$ and the control group $79,8 \pm$ 8,0 to $82,5 \pm 7,0$ ( $p<0.05$ for both) and for $\%$ of fat, Paleo group reduced on average to $18.3 \pm$ 5.3 and $15.8 \pm 4.8$ and control group, $20,1 \pm 8,0$ to $17.4 \pm 7.0$, both showed $\mathrm{P}<0.05$ too.

\section{Conclusions}

It can be concluded that the Paleolithic diet seemed to favor the loss of muscle strength in upper limbs but has not had influence on any other parameters.

\section{Acknowledgement} FCA/UNICAMP, PIBIC/UNICAMP. CAPES,
FAPESP.

${ }^{1}$ THOMPSON, WR. Worldwide Survey of Fitness Trends for 2014 ACSM'S Health \& Fitness J. 2013: 17: (6): 10-20 